\title{
Universiteit
}

Leiden

The Netherlands

\section{Risk of a first venous thrombotic event in carriers of a familial thrombophilic defect. The European Prospective Cohort on Thrombophilia (EPCOT)}

Vossen, C.Y.; Conard, J.; Fontcuberta, J.; Makris, M.; Meer, F.J.M. van der; Pabinger, I.; ... ; Rosendaal, F.R.

\section{Citation}

Vossen, C. Y., Conard, J., Fontcuberta, J., Makris, M., Meer, F. J. M. van der, Pabinger, I., ... Rosendaal, F. R. (2005). Risk of a first venous thrombotic event in carriers of a familial thrombophilic defect. The European Prospective Cohort on Thrombophilia (EPCOT). Journal Of Thrombosis And Haemostasis, 3(3), 459-464. Retrieved from https://hdl.handle.net/1887/5056

Version: $\quad$ Not Applicable (or Unknown)

License:

Downloaded from: https://hdl.handle.net/1887/5056

Note: To cite this publication please use the final published version (if applicable). 


\title{
Risk of a first venous thrombotic event in carriers of a familial thrombophilic defect. The European Prospective Cohort on Thrombophilia (EPCOT)
}

\author{
C. Y. VOSSEN, * J. CONARD, † J. FONTCUBERTA, $\$$ M. MAKRIS, § F. J. M. VAN DER MEER,

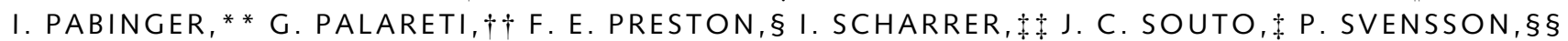 \\ I. D. WALKER $\uparrow$ and F. R. ROSENDAAL* \\ *Department of Clinical Epidemiology, Leiden University Medical Center, Leiden, the Netherlands; †Department of Biological Haematology, \\ Hôtel-Dieu Hospital, Paris, France; $\$$ Department of Haematology, Hospital de la Santa Creu i Sant Pau, Barcelona, Spain; §Department of \\ Haematology, Royal Hallamshire Hospital, Sheffield, UK; $\uparrow$ Department of Haematology, Leiden University Medical Center, Leiden, the \\ Netherlands; **Department of Haematology and Haemostaseology, University Hospital Vienna, Vienna, Austria; ††Department of Angiology and \\ Blood Coagulation, University Hospital S. Orsola, Bologna, Italy; †+Department of Internal Medicine, University Hospital, Frankfurt/Main, \\ Germany; §§Department for Coagulation Disorders, University Hospital, Malmö, Sweden; and ๑ Department of Haematology, Glasgow Royal \\ Infirmary, Glasgow, UK
}

\begin{abstract}
To cite this article: Vossen CY, Conard J, Fontcuberta J, Makris M, van der Meer FJM, Pabinger I, Palareti G, Preston FE, Scharrer I, Souto JC, Svensson P, Walker ID, Rosendaal FR. Risk of a first venous thrombotic event in carriers of a familial thrombophilic defect. The European Prospective Cohort on Thrombophilia (EPCOT). J Thromb Haemost 2005; 3: 459-64.
\end{abstract}

See also Spencer FA, Goldberg RJ. Asymptomatic thrombophilia-a family affair. This issue, pp 457-8.

Summary. Background: Reliable risk estimates for venous thrombosis in families with inherited thrombophilia are scarce but necessary for determining optimal screening and treatment policies. Objectives: In the present analysis, we determined the risk of a first venous thrombotic event in carriers of a thrombophilic defect (i.e. antithrombin-, protein C- or protein $\mathrm{S}$ deficiency, or factor V Leiden). Patients and methods: The asymptomatic carriers had been tested prior to this study in nine European thrombosis centers because of a symptomatic carrier in the family, and were followed prospectively for 5.7 years on average between March 1994 and January 2001. Annually, data were recorded on the occurrence of risk situations for venous thrombosis and events (e.g. venous thrombosis, death). Results: Twenty-six of the 575 asymptomatic carriers (4.5\%) and seven of the 1118 controls $(0.6 \%)$ experienced a first deep venous thrombosis or pulmonary embolism during follow-up. Of these events, $58 \%$ occurred spontaneously in the carriers compared with $43 \%$ in the controls. The incidence of first events was $0.8 \%$ per year (95\% CI 0.5-1.2) in the carriers compared with $0.1 \%$ per year $(95 \%$ CI $0.0-0.2)$ in the controls. The highest incidence

Correspondence: Professor F. R. Rosendaal MD, Department of Clinical Epidemiology, Leiden University Medical Center, PO Box 9600, 2300 RC Leiden, the Netherlands.

Tel.: +31 71 5264037; fax: +31 5266994; e-mail: F.R.Rosendaal@ lumc.nl

Received 12 August 2004, accepted 18 November 2004 was associated with antithrombin deficiency or combined defects, and the lowest incidence with factor $\mathrm{V}$ Leiden. Conclusions: The incidence of venous events in asymptomatic individuals from thrombophilic families does not exceed the risk of bleeding associated with long-term anticoagulant treatment in the literature $(1-3 \%)$.

Keywords: asymptomatic, inherited thrombophilia, venous thrombosis.

\section{Introduction}

Venous thrombosis has an overall incidence of about 1-2 per 1000 individuals per year and is a serious disorder with potential major complications such as death from pulmonary embolism, recurrences and the development of a disabling postthrombotic syndrome [1-3]. It has been postulated that not a single risk factor, but interaction between multiple genetic and environmental risk factors is a prerequisite for venous thrombosis to develop [4-6]. Currently, several genetic risk factors are known to increase the risk of venous thrombosis: deficiencies in the anticoagulation factors protein $\mathrm{C}$, protein $\mathrm{S}$ and antithrombin, and the factor V Leiden and prothrombin G20210A mutations [7-11]. In accordance with the multicausal nature of thrombosis, it was found that the presence of a family history of venous thrombosis increases the thrombotic risk in individuals with protein $\mathrm{C}$ deficiency or factor $\mathrm{V}$ Leiden, due most probably to the concomitant presence of other genetic or environmental risk factors within the family $[6,12,13]$. 
A prerequisite to determining the optimal clinical approach, e.g. with regard to screening or (long-term) prophylactic anticoagulant treatment in families with inherited thrombophilia is to define the absolute risk of venous thrombosis, and to weigh this risk against the risk of bleeding complications associated with prophylactic treatment. To obtain valid risk estimates of the absolute risk of venous thrombosis in families with inherited thrombophilia, we started the European Prospective Cohort on Thrombophilia (EPCOT) study. The EPCOT study, by combining data from nine centers, is the largest prospective cohort of individuals with deficiencies of protein $\mathrm{C}$, protein $\mathrm{S}$ and antithrombin and factor $\mathrm{V}$ Leiden. In this paper, we present data on the risk of a first venous thromboembolic event associated with inherited thrombophilia in relatives of probands from thrombophilic families who were asymptomatic at the time of inclusion in the study.

\section{Methods}

\section{Participants}

The design of the study has been described in detail previously [14]. In short, inclusion of the participants took place between March 1994 and September 1997 with prospective follow-up until January 2001. Nine centers from eight countries (Austria, France, Germany, Italy, Spain, Sweden, the Netherlands and the United Kingdom) participated. Each center enrolled all registered probands (first of a family in whom thrombophilia was detected) with a deficiency of protein $\mathrm{C}$, protein $\mathrm{S}$ or antithrombin or factor $\mathrm{V}$ Leiden, and their registered relatives with one of these defects. Healthy partners or, if there were none, friends or acquaintances of participating individuals with inherited thrombophilia were included as controls. Controls were excluded if they were known to have heritable thrombophilia, or if they were related to a participant with an inherited thrombotic defect. Controls were, however, not tested for any of the defects under study after study entry. All participants gave informed consent. Data were collected at baseline, and annually during follow-up. At study entry data were collected on subjects' general demographics, hereditary defect [type, subtype (if available), levels (if available), information on DNA testing], current medication and current risk factors for thrombosis, history of thrombosis, obstetric history and family history of thrombosis. The data recorded at follow-up included the occurrence of risk situations [surgery, hospital admission, plaster casts, prolonged bed rest ( $>2$ weeks), traveling ( $>8 \mathrm{~h}$ ), details on pregnancies, medication)] and on outcome events (e.g. venous thrombosis, hemorrhage, death). Completed forms were sent to the coordinating center with only the patient identifier's code to protect patient confidentiality.

From a total of 1626 individuals with thrombophilic defects and 1212 control subjects, this paper includes only relatives of probands who had not previously experienced any venous thrombotic event [deep venous thrombosis (DVT), pulmonary embolism (PE), or superficial thrombophlebitis (STP)] before inclusion in the study, and who did not receive long-term prophylactic oral anticoagulant treatment during prospective follow-up (defined as treatment for at least 1 year without interruptions). Twenty thrombophilic individuals received long-term prophylactic oral anticoagulant treatment: 10 for prevention of venous thrombosis and 10 for a personal history of arterial disease. Eight controls received long-term anticoagulation treatment for an arterial indication. In addition, we only included relatives of probands tested because of venous thrombosis or a positive family history. Families in which thrombophilia was detected because of screening before hormone prescription or research purposes were not included, in an effort to stay as close as possible to the real-life situation of an individual from a symptomatic thrombophilia family asking a physician for advice.

Recruitment was before description of the G20210A mutation in the prothrombin gene, but during prospective follow-up we gathered information on the presence of this mutation as an additional defect.

\section{Quality assessment thrombophilia testing and verification of events}

The participating centers performed the various assays according to their local protocol and participated in an external quality assessment scheme for thrombophilia testing. For the first 2 years this was the quality assurance scheme developed for the European Concerted Action on Thrombosis (ECAT/ EQAS) (Leiden) and for the subsequent years the UK National External Quality Assessment Service (NEQAS) (Sheffield, UK).

Per center, a local investigator verified all events in prospective follow-up. In case of death the autopsy data were collected, if available. An adjudication committee scored all reported events independently after receiving all the relevant medical information from each center, but in case of doubt or when no consensus was reached at first, further information was asked for (e.g. actual test results). Committee members were not blinded for whether a person was a thrombophilia carrier or control, but were unaware of the type of defect of the carriers. Venous thromboses were classified as definite venous events when they were objectively confirmed, i.e. for DVT by ultrasound (duplex, Doppler), impedance plethysmography, venography or leg symptoms plus definite PE, and for PE by angiography, high probability ventilation-perfusion-scan, spiral computerized tomography or autopsy. STPs were considered definite events when diagnosed by a physician. For the analysis reported here, we included only definite venous events. Consensus on the classification of the venous events, i.e. that a majority of the steering committee members agreed, was reached in 67 of the $72(93 \%)$ reported events during prospective follow-up (47 DVTs or PEs, 21 STPs, four major hemorrhages). Of the remaining five events which were classified as definite DVT or PE $(n=4)$ or no PE $(n=1)$, consensus was reached after additional information was provided $(n=4)$ or after reconsideration $(n=1)$. For controls, immediate consensus was reached in $88 \%$ of the reported 
events (15 of 17) and in thrombophilic subjects in $95 \%$ of the reported events (52 of 55).

\section{Analysis and statistics}

We calculated the annual absolute risk (incidence) and relative risk of a first DVT or PE for various groups in the cohort. The incidence of venous thrombotic events was calculated by dividing the number of events by the total of observation-years (follow-up time). Follow-up time was the time between inclusion and the event of interest, death or the last date of follow-up (the end of the study or last date before loss to follow-up), whichever occurred first. A DVT or PE was considered first event only when not preceded by a STP. If a PE followed a DVT within 3 months, these events were considered a single event. The $95 \%$ confidence intervals (95\% CI) were calculated according to a Poisson distribution for the number of events [15]. Hazard ratios as estimation of the relative risk of venous thrombosis were calculated by Cox-regression with venous thrombosis as the dependent variable and presence or absence of thrombophilia as independent variable. Center, age (as stratum: age $<45$ or $\geq 45$ ) and sex were entered in the Cox-regression model to adjust for center, age and sex effects.

\section{Results}

We collected prospective data on 575 relatives with a thrombophilic defect and 1118 controls ( 825 partners, 293 friends), all without a thrombotic event prior to inclusion and not on longterm oral anticoagulant treatment. The total follow-up time was 3283 years in the individuals with thrombophilia (mean 5.7; range 0.2-7.3) and 6289 years in the controls (mean 5.6; range 0.7-7.2). During follow-up, 20 thrombophilic subjects and 64 controls were lost to follow-up (complete follow-up in $95 \%$ ), and eight thrombophilic individuals and 12 controls died. The causes of death in the carriers were heart disease $(n=3)$, suspected pulmonary embolism $(n=1)$ and other causes $(n=4)$. Causes of death in controls were not related to venous thrombosis (cancer $(n=4)$, myocardial infarction $(n=4)$, accidents in traffic or at work $(n=3)$ or surgery $(n=1))$. The main characteristics at inclusion are shown in Table 1. A preponderance of the thrombophilic individuals was female $(62 \%)$, whereas sex was distributed more equally among the controls.

\section{Risk of a first event}

Of the 575 thrombophilic individuals, 26 thrombophilic subjects experienced a first DVT or PE during follow-up $(4.5 \%)$ (one relative had a mesenteric vein thrombosis) compared with seven of the 1118 controls $(0.6 \%)$ (Table 2$)$. The events occurred spontaneously, i.e. did not occur after exposure to a known acquired risk factor, in 15 thrombophilic individuals $(58 \%)$ and three controls $(43 \%)$. The risk factors present at the time of the event in the remaining 11 thrombophilic individuals were hospitalization $(n=3)$, hormone
Table 1 General characteristics at inclusion

\begin{tabular}{lll}
\hline & $\begin{array}{l}\text { Thrombophilic } \\
\text { individuals }\end{array}$ & Controls \\
\hline All $(n)$ & 575 & 1118 \\
Men $(n)$ & 214 & 588 \\
Women $(n)$ & 361 & 530 \\
OCC use, age $10-50(n / \text { total } N)^{*}$ & $63 / 265$ & $153 / 360$ \\
HRT use, age $\geq 50(n /$ total $N)$ & $17 / 77$ & $47 / 159$ \\
PC deficiency $(n)$ & 143 & NA \\
PS deficiency $(n)$ & 107 & NA \\
AT deficiency $(n)$ & 96 & NA \\
FVL $(n)$ & $173^{\mathrm{a}}$ & NA \\
Combined defects $(n)$ & 56 & NA \\
PC-PS $(n)$ & 1 & NA \\
FVL-PC $(n)$ & 11 & NA \\
FVL-PS $(n)$ & 15 & NA \\
FVL-AT $(n)$ & 6 & NA \\
FVL-PT20210A $(n)$ & $8^{\mathrm{b}}$ & NA \\
PT20210A-PC $(n)$ & 9 & NA \\
PT20210A-PS $(n)$ & $4^{\mathrm{c}}$ & NA \\
PT20210A-AT $(n)$ & 2 & NA \\
Mean age at inclusion $($ years (range) $)$ & $35(0-91)$ & $41(3-87)$ \\
Mean BMI $\left(\mathrm{kgm}^{-2}(\right.$ range) $) * *$ & $23(13-42)$ & $24(13-39)$ \\
Cancer ever $(n(\%))$ & $8(1)$ & $12(1)$ \\
& &
\end{tabular}

$\mathrm{OCC}=$ oral contraceptives, HRT $=$ hormone replacement therapy, $\mathrm{PC}=$ protein $\mathrm{C}, \mathrm{PS}=$ protein $\mathrm{S}, \mathrm{AT}=$ antithrombin, $\mathrm{FVL}=$ factor V Leiden, PT20210A = prothrombin G20210A, NA = not applicable, $\mathrm{BMI}=$ body mass index. ${ }^{\mathrm{a}} 10$ were homozygous; ${ }^{\mathrm{b}}$ one was homozygous for factor V Leiden; "one was homozygous for prothrombin G20210 A. *The oral contraceptives contained estrogen in $34 / 265$ $(13 \%)$ thrombophilic women and 139/360 (39\%) of the control women. ** Information on BMI was available for 574 thrombophilic individuals and 1117 controls.

replacement therapy $(n=2)$, infection $(n=2)$, pregnancy $(n=2)$, cancer $(n=1)$ and oral contraceptives $(n=1)$, and in the four remaining controls surgery $(n=2)$, hospitalization $(n=1)$ and cancer $(n=1)$. The incidence of a first DVT or PE was higher in the thrombophilic individuals than in the controls, respectively, $0.8 \%$ per year $(95 \%$ CI $0.5-1.2)$ compared with $0.1 \%$ per year $(95 \%$ CI $0.0-0.2)$ (Table 2$)$ with a relative risk of 9.0 (95\% CI 3.8-21.1), adjusted for sex, age at entry and center effects (crude relative risk: 7.3 ; 95\% CI 3.2 16.8). The incidence of a STP as first event was $0.5 \%$ per year (95\% CI $0.3-0.8)$ in the thrombophilic subjects and $0.1 \%$ per year $(95 \%$ CI $0.0-0.2)$ in the controls (Table 2$)$ with a relative risk of 5.2 (95\% CI 2.0-13.7), adjusted for sex, age at entry and center effects (crude relative risk: 5.3; 95\% CI 2.1-13.5).

The annual incidence of a first DVT or PE was highest for thrombophilic individuals with antithrombin deficiency $(1.7 \%$ year $^{-1} ; 95 \%$ CI $0.8-3.3$ ) or combined defects ( $1.6 \%$ year $^{-1} ; 95 \%$ CI $0.5-3.7)$ and lowest in thrombophilic individuals with the factor $\mathrm{V}$ Leiden mutation $\left(0.1 \%\right.$ year $^{-1} ; 95 \%$ CI $\left.0.0-0.6\right)$ (Table 2). Unfortunately, the numbers per type of defect were too small to estimate the risks by age and sex. Our database contained subtype information (or sufficient level information to determine the subtype) of 120 protein $\mathrm{C}$ deficient individuals, 97 individuals with protein $\mathrm{S}$ deficiency and 76 individuals with antithrombin deficiency. When we included in the analysis only 
Table 2 Incidence $\left(\%\right.$ year $\left.^{-1}\right)$ and age at onset of a first venous thrombosis

\begin{tabular}{|c|c|c|c|c|c|}
\hline & Total subjects, $n$ & $\mathrm{DVT} / \mathrm{PE}, n$ & $\begin{array}{l}\text { Age onset, } \\
\text { years (range) }\end{array}$ & Person-years, $n$ & $\begin{array}{l}\text { Incidence, } \\
(95 \% \mathrm{CI})\end{array}$ \\
\hline Thrombophilic individuals & 575 & 26 & $40(20-65)$ & 3194.4 & $0.8(0.5-1.2)$ \\
\hline PC deficiency & 143 & 6 & $41(22-65)$ & 833.2 & $0.7(0.3-1.6)$ \\
\hline PS deficiency & 107 & 5 & $38(28-63)$ & 619.1 & $0.8(0.3-1.9)$ \\
\hline AT deficiency & 96 & 9 & $39(21-58)$ & 520.6 & $1.7(0.8-3.3)$ \\
\hline FVL & 173 & $1 *$ & 63 & 902.1 & $0.1(0.0-0.6)$ \\
\hline Combined defects & 56 & $5^{*}$ & $36(20-62)$ & 319.4 & $1.6(0.5-3.7)$ \\
\hline Males & 214 & 16 & $37(20-65)$ & 1162.0 & $1.4(0.8-2.2)$ \\
\hline Females & 361 & 10 & $44(21-65)$ & 2032.4 & $0.5(0.2-0.9)$ \\
\hline Age at inclusion $18-45$ years & 339 & 18 & $32(21-47)$ & 1880.1 & $1.0(0.6-1.5)$ \\
\hline Age at inclusion above 45 years & 146 & 7 & $61(51-65)$ & 793.2 & $0.9(0.4-1.8)$ \\
\hline Controls & 1118 & 7 & $63(38-84)$ & 6269.6 & $0.1(0.0-0.2)$ \\
\hline Males & 588 & 2 & $58(57-59)$ & 3303.0 & $0.1(0.0-0.2)$ \\
\hline Females & 530 & 5 & $64(38-84)$ & 2966.6 & $0.2(0.1-0.4)$ \\
\hline Age at inclusion $18-45$ years & 652 & 1 & 38 & 3601.8 & $0.0(0.0-0.2)$ \\
\hline Age at inclusion above 45 years & 426 & 6 & $67(57-84)$ & 2445.7 & $0.2(0.1-0.5)$ \\
\hline
\end{tabular}

$\overline{\mathrm{DVT}}=$ deep venous thrombosis, $\mathrm{PE}=$ pulmonary embolism, $\mathrm{CI}=$ confidence interval, $\mathrm{PC}=$ protein $\mathrm{C}, \mathrm{PS}=$ protein $\mathrm{S}, \mathrm{AT}=$ antithrombin, $\mathrm{FVL}=$ factor V Leiden. *All were heterozygous.

individuals known to have subtype I (103 with protein C deficiency, 68 with protein S deficiency and 59 with antithrombin deficiency), the risk of a major event was similar to the risk in Table 2. The risk of thrombosis in those with a type II defect or type III protein S defect was not lower than in those with type I abnormalities, although the number of individuals $(n=63)$ with type II or III defects was low (results not shown).

In men with thrombophilia, the annual incidence of a first DVT or PE was higher $\left(1.4 \%\right.$ year $^{-1} ; 95 \%$ CI $\left.0.8-2.2\right)$ compared with thrombophilic women $\left(0.5 \% \mathrm{year}^{-1} ; 95 \%\right.$ CI $\left.0.2-0.9\right)$ (Table 2). In controls, the incidences of a first DVT or PE did not differ between the sexes (Table 2). The percentage of women above the age of 50 using hormone replacement therapy was slightly lower in thrombophilic women (22\%) compared with controls $(30 \%)$, whereas a much lower percentage of women with inherited thrombophilia used estrogen-containing oral contraceptives (13\%; age 10-50 years) compared with the control women ( $39 \%$; age $10-50$ years). The incidence of a first DVT or PE in thrombophilic women who did not use oral contraceptives (age $10-50$ years) was $0.4 \%$ year $^{-1}(95 \%$ CI $0.1-0.9)$ compared with $0.5 \%$ year $^{-1}(95 \%$ CI $0.0-2.9)$ in women using estrogen-containing oral contraceptives.
The first DVT or PE occurred about 20 years earlier in the thrombophilic individuals than in the controls (Table 2). The mean age at onset was $\sim 40$ years for individuals with protein C-, protein S- or antithrombin deficiency or combined defects and 63 years for the subject with factor $\mathrm{V}$ Leiden, in comparison to 63 years in the controls (Table 2).

The risk of a first DVT or PE was $1.0 \%$ per year $(95 \%$ CI 0.6-1.6) among the 285 thrombophilic individuals who encountered acquired risk factors during prospective followup and who did not receive short-term anticoagulation during these risk situations (i.e. surgery, hospitalization, bed rest for more than 13 days, plaster cast, cancer, pregnancy or traveling for more than $8 \mathrm{~h}$ ). Table 3 shows the frequency of venous events associated with the presence of acquired risk factors during prospective follow-up for which no short-term prophylactic anticoagulant treatment was provided. Cancer, although the number of individuals was small, and pregnancy appear to be the risk factors during which most secondary venous events occurred in the thrombophilic individuals. The incidence of a first DVT or PE in the 156 thrombophilic individuals who did not encounter acquired risk factors for which they could have received short-term anticoagulation

Table 3 Number of first venous events per risk situation for which subjects did not receive short-term prophylactic anticoagulation

\begin{tabular}{|c|c|c|c|c|c|c|}
\hline & \multicolumn{3}{|c|}{ Thrombophilic individuals } & \multicolumn{3}{|c|}{ Controls } \\
\hline & $n$ & Situations $n$ & $\mathrm{DVT} / \mathrm{PE}, n(\%)$ & $n$ & Situations $n$ & $\mathrm{DVT} / \mathrm{PE}, n(\%)$ \\
\hline Travel $(>8 \mathrm{~h})$ & 260 & $504 *$ & $0(0 \%)$ & 567 & $1244^{*}$ & $0(0 \%)$ \\
\hline Surgery/immobilization** & 143 & 176 & $3(2 \%)$ & 290 & 407 & $2(0 \%)$ \\
\hline Plaster cast & 27 & 33 & $0(0 \%)$ & 59 & 71 & $0(0 \%)$ \\
\hline Cancert & 10 & 10 & $1(10 \%)$ & 17 & 17 & $1(6 \%)$ \\
\hline Pregnancies & 24 & 28 & $2(7 \%)$ & 61 & 75 & $0(0 \%)$ \\
\hline
\end{tabular}

$\mathrm{DVT}=$ deep venous thrombosis, $\mathrm{PE}=$ pulmonary embolism. ${ }^{*}$ The number of follow-up years in which individuals reported to have traveled at least once for more than 8 hours. **Immobilization is defined as a hospital stay, or bed rest for at least 14 days at home. $\dagger$ Defined as malignancy still present or developed during prospective follow-up. Nine (four thrombophilic individuals, five controls) received anticoagulation during and after surgery for cancer. 
during prospective follow-up was, however, similar: $0.8 \%$ per year (95\% CI 0.3-1.7).

A total of 134 thrombophilic individuals $(23 \%)$ received short-term prophylactic anticoagulation during one or more risk situations: surgery $(n=95)$, pregnancy $(n=43$; 13 during puerperium only; range start treatment during pregnancy: weeks 5-36), plaster cast $(n=13)$, traveling $(n=9)$ and after twisting a knee or an ankle $(n=2)$. No venous events occurred during any of these risk situations under short-term prophylactic anticoagulant treatment. Of the controls, $115(10 \%)$ also received short-term anticoagulant treatment during risk situations: during surgery $(n=107)$, pregnancy $(n=4 ; 3$ during puerperium only), plaster cast $(n=12)$, traveling $(n=1)$ and after twisting a knee $(n=1)$ or during chronic enteritis $(n=1)$.

\section{Discussion}

We conducted a large prospective follow-up study in nine centers in eight countries on 1626 probands and relatives, and 1212 controls to obtain valid estimates of the risk of venous thrombosis in families with inherited thrombophilia. In the present report, we describe the risk of a first venous thromboembolic event in 575 thrombophilic individuals and 1118 control subjects who were followed-up to 7 years (mean followup 5.6 years) and who were asymptomatic and not on longterm anticoagulant treatment at study inclusion.

Among the thrombophilic individuals, the annual risk of a first DVT or PE was $0.8 \%$ per year. The incidence was lowest for thrombophilic individuals with factor $\mathrm{V}$ Leiden $\left(0.1 \%\right.$ year $\left.^{-1}\right)$ and highest for thrombophilic subjects with antithrombin deficiency $\left(1.7 \%\right.$ year $\left.^{-1}\right)$, individuals with combined defects $\left(1.6 \%\right.$ year $\left.^{-1}\right)$ and men $\left(1.4 \%\right.$ year $\left.^{-1}\right)$. DVTs and PEs occurred spontaneously in 58\% of the thrombophilic individuals and $43 \%$ of the controls. The annual risk was not increased in thrombophilic individuals who encountered additional acquired risk situations (e.g. surgery, immobilization, pregnancy, plaster cast) during which no short-term anticoagulation treatment was prescribed. As 134 thrombophilic individuals did receive shortterm anticoagulation during risk situations, mainly during pregnancy and surgery, this finding could be the result of the intention of doctors to treat those with a high risk of venous thrombosis only in definite high-risk situations.

The strongest point of this study is its size: deficiencies of natural anticoagulants are rare, and large prospective studies are therefore scarce. We excluded events that were not objectively confirmed; as these were few and equally distributed over thrombophilic individuals and controls (of the DVTs and PEs $12 \%$ were non-definite in the carriers compared with $14 \%$ in the controls) this could not have affected our results. The results of this study should not be generalized to all individuals with thrombophilia, as we focused on asymptomatic subjects with familial thrombophilia, to which patient group these results apply. We have shown previously that the risk of thrombosis is higher in selected individuals from families with a clear familial thrombophilia than in unselected individuals without a strong family history, regardless of the defect $[12,13]$. Other studies on the risk of a first venous thrombotic event in carriers of a hereditary defect [16-22] reported annual incidences of venous thrombosis ranging from $0.4 \%$ to $2.5 \%$ for protein $\mathrm{C}$ deficiency, $0.1 \%$ to $3.2 \%$ for protein $\mathrm{S}$ deficiency and $0.9 \%$ to $2.9 \%$ for antithrombin deficiency. For factor $\mathrm{V}$ Leiden, the reported incidences ranged from $0.1 \%$ to $0.7 \%$ per year $[17,19,23-25]$. The risks found in the present study could have been underestimated due to preventative measures taken by the treating physicians, who were aware of the presence of a thrombophilic defect, to reduce the risk of venous thrombosis. However, the risk for individuals with single defects might have been overestimated when they carried the prothrombin G20210A mutation, but were not tested for this particular mutation in our study. We were able to gather information on the presence of this mutation as an additional defect for 360 of the 575 thrombophilic individuals $(63 \%)$.

Although the risk of a first DVT or PE was increased in thrombophilic individuals, the risk was still low and did not outweigh the reported risk of $1-3 \%$ of hemorrhagic complications in patients with prolonged anticoagulant therapy with target INRs with a lower limit of 2.0 [26,27]. Therefore, longterm prophylactic anticoagulant treatment does not seem beneficial in asymptomatic relatives of symptomatic probands with inherited thrombophilia, although future prophylactic treatment options with a lower risk of bleeding might change this. However, there might be a need for a more stringent thromboprophylactic treatment policy during temporary periods of increased thrombotic risk as no DVT or PE occurred in thrombophilic individuals during risk situations in which prophylactic anticoagulation was used. In the thrombophilic individuals, $42 \%$ of all DVTs or PEs occurred in the presence of a known risk situation and could therefore have been prevented.

Whether screening or short-term prophylaxis would be beneficial is difficult to conclude from our results, as the low risk of thrombosis might be the result of screening and a policy aimed at preventing thrombosis, as can be deduced from the low number of women with estrogen-containing oral contraceptives and the high number of women with prophylactic anticoagulant therapy during pregnancy or puerperium. Further studies should elucidate whether a more stringent policy of thromboprophylaxis in risk situations could further reduce the risk of thrombosis, which should in particular focus on individuals with antithrombin deficiency and combined defects, who had the highest risk of thrombosis.

\section{Addendum}

F. R. Rosendaal originated and coordinated the study together with F. E. Preston, E. Briët, I. D. Walker and J. Fontcuberta (the study steering committee). The first author, C. Y. Vossen, performed the analyses and wrote the manuscript. All other authors were involved in designing the study and involved in collecting patient data and reviewing the manuscript. 


\section{Acknowledgements}

The study was supported by BIOMED II grant number BMHI-CT94-1565 (coordinator F. R. Rosendaal). We thank E. Briët, I. de Jonge, L. Velmans, W. Noteboom (Leiden), P. Bayliss (Sheffield), M. J. Gallego (Barcelona), E. AygörenPürsün, M. Krause (Frankfurt am Main), C. Legnani (Bologna), E. Berntorp, V. Meha (Malmö) and S. Koder (Vienna) for their contributions to the study.

\section{References}

1 Anderson FA Jr, Brownell Wheeler H, Goldberg RJ, Hosmer DW, Patwardhan NA, Jovanovic B, Forcier A, Dalen JE. A populationbased perspective of the hospital incidence and case- fatality rates of deep vein thrombosis and pulmonary embolism. The Worcester DVT Study. Arch Intern Med 1991; 151: 933-8.

2 Nordström M, Lindblad B, Bergqvist D, Kjellström T. A prospective study of the incidence of deep-vein thrombosis within a defined urban population. J Intern Med 1992; 232: 155-60.

3 Prandoni P, Lensing AW, Cogo A, Cuppini S, Villalta S, Carta M, Cattelan AM, Polistena P, Bernardi E, Prins MH. The long-term clinical course of acute deep venous thrombosis. Ann Intern Med 1996; 125: $1-7$.

4 Rosendaal FR. Venous thrombosis: a multicausal disease. Lancet 1999; 353: 1167-73.

5 Seligsohn U, Zivelin A. Thrombophilia as a multigenic disorder. Thromb Haemost 1997; 78: 297-301.

6 Bovill EG, Hasstedt SJ, Leppert MF, Long GL. Hereditary thrombophilia as a model for multigenic disease. Thromb Haemost 1999; 82: $662-6$.

7 Thaler E, Lechner K. Antithrombin III deficiency and thromboembolism. Clin Haematol 1981; 10: 369-90.

8 Broekmans AW, Veltkamp JJ, Bertina RM. Congenital protein C deficiency and venous thromboembolism. A study of three Dutch families. $N$ Engl J Med 1983; 309: 340-4.

9 Broekmans AW, Bertina RM, Reinalda-Poot J, Engesser L, Muller HP, Leeuw JA, Michiels JJ, Brommer EJ, Briët E. Hereditary protein $\mathrm{S}$ deficiency and venous thrombo-embolism. A study in three Dutch families. Thromb Haemost 1985; 53: 273-7.

10 Bertina RM, Reitsma PH, Rosendaal FR, Vandenbroucke JP. Resistance to activated protein $\mathrm{C}$ and factor $\mathrm{V}$ Leiden as risk factors for venous thrombosis. Thromb Haemost 1995; 74: 449-53.

11 Poort SR, Rosendaal FR, Reitsma PH, Bertina RM. A common genetic variation in the $3^{\prime}$-untranslated region of the prothrombin gene is associated with elevated plasma prothrombin levels and an increase in venous thrombosis. Blood 1996; 88: 3698-703.

12 Lensen RP, Rosendaal FR, Koster T, Allaart CF, de Ronde H, Vandenbroucke JP, Reitsma PH, Bertina RM. Apparent different thrombotic tendency in patients with factor $\mathrm{V}$ Leiden and protein $\mathrm{C}$ deficiency due to selection of patients. Blood 1996; 88: 4205-8.

13 Lensen RP, Bertina RM, de Ronde H, Vandenbroucke JP, Rosendaal FR. Venous thrombotic risk in family members of unselected individuals with factor V Leiden. Thromb Haemost 2000; 83: 817-21.

14 Vossen CY, Conard J, Fontcuberta J, Makris M, van der Meer FJ, Pabinger I, Palareti G, Preston FE, Scharrer I, Souto JC, Svensson P,
Walker ID, Rosendaal FR. Familial thrombophilia and lifetime risk of venous thrombosis. J Thromb Haemost 2004; 2: 1526-32.

15 Wissenschaftliche Tabellen Geigy. Teilband Statistik, Vol. 8. Basel, 1980: 152.

16 Bucciarelli P, Rosendaal FR, Tripodi A, Mannucci PM, De Stefano V, Palareti G, Finazzi G, Baudo F, Quintavalla R. Risk of venous thromboembolism and clinical manifestations in carriers of antithrombin, protein $\mathrm{C}$, protein $\mathrm{S}$ deficiency, or activated protein $\mathrm{C}$ resistance: a multicenter collaborative family study. Arterioscler Thromb Vasc Biol 1999; 19: 1026-33.

17 Tirado I, Mateo J, Soria JM, Oliver A, Borrell M, Coll I, Vallvé C, Souto JC, Martínez-Sánchez E, Fontcuberta J. Contribution of prothrombin 20210A allele and factor V Leiden mutation to thrombosis risk in thrombophilic families with other hemostatic deficiencies. Haematologica 2001; 86: 1200-8.

18 Sanson BJ, Simioni P, Tormene D, Moia M, Friederich PW, Huisman MV, Prandoni P, Bura A, Rejtő L, Wells P, Mannucci PM, Girolami A, Büller HR, Prins MH. The incidence of venous thromboembolism in asymptomatic carriers of a deficiency of antithrombin, protein $\mathrm{C}$, or protein S: a prospective cohort study. Blood 1999; 94: 3702-6.

19 Martinelli I, Mannucci PM, De Stefano V, Taioli E, Rossi V, Crosti F, Paciaroni K, Leone G, Faioni EM. Different risks of thrombosis in four coagulation defects associated with inherited thrombophilia. a study of 150 families. Blood 1998; 92: 2353-8.

20 De Stefano V, Leone G, Mastrangelo S, Tripodi A, Rodeghiero F, Castaman G, Barbui T, Finazzi G, Bizzi B, Mannucci PM. Clinical manifestations and management of inherited thrombophilia. retrospective analysis and follow-up after diagnosis of 238 patients with congenital deficiency of antithrombin III, protein C, protein S. Thromb Haemost 1994; 72: 352-8.

21 van Boven HH, Vandenbroucke JP, Briët E, Rosendaal FR. Genegene and gene-environment interactions determine risk of thrombosis in families with inherited antithrombin deficiency. Blood 1999; 94: $2590-4$.

22 Pabinger I, Kyrle PA, Heistinger M, Eichinger S, Wittmann E, Lechner K. The risk of thromboembolism in asymptomatic patients with protein $\mathrm{C}$ and protein $\mathrm{S}$ deficiency: a prospective cohort study. Thromb Haemost 1994; 71: 441-5.

23 Lensen R, Rosendaal F, Vandenbroucke J, Bertina R. Factor V Leiden: the venous thrombotic risk in thrombophilic families. $\mathrm{Br} J$ Haematol 2000; 110: 939-45.

24 Simioni P, Tormene D, Prandoni P, Zerbinati P, Gavasso S, Cefalo P, Girolami A. Incidence of venous thromboembolism in asymptomatic family members who are carriers of factor V Leiden: a prospective cohort study. Blood 2002; 99: 1938-42.

25 Middeldorp S, Meinardi JR, Koopman MM, van Pampus EC, Hamulyák K, van der Meer J, Prins MH, Büller HR. A prospective study of asymptomatic carriers of the factor V Leiden mutation to determine the incidence of venous thromboembolism. Ann Intern Med 2001; 135: 322-7.

26 van der Meer FJ, Rosendaal FR, Vandenbroucke JP, Briët E. Bleeding complications in oral anticoagulant therapy. An analysis of risk factors. Arch Intern Med 1993; 153: 1557-62.

27 Palareti G, Leali N, Coccheri S, Poggi M, Manotti C, D'Angelo A, Pengo V, Erba N, Moia M, Ciavarella N, Devoto G, Berrettini M, Musolesi S. Bleeding complications of oral anticoagulant treatment: an inception-cohort, prospective collaborative study (ISCOAT). Italian Study on Complications of Oral Anticoagulant Therapy. Lancet 1996; 348: 423-8. 